Where magnetic clutches are used it is desirable to have all three bearings mounted on a common iron base to preserve the alinement, but such construction is not necessarily required. The iron base may be omitted and the out-board bearing mounted on a concrete foundation.

\title{
Magnetic Clutches in the Cement Industry
}

\author{
BY W. H. COSTELLO \\ Member, A. I. E. E. \\ Cutler-Hammer Manufacturing Company, Milwaukee, Wis.
}

$\mathbf{I}^{\mathrm{N}}$ $\mathrm{N}$ the early days of the cement industry, when grinding units were of relatively small capacity, motors of $75 \mathrm{~h}$. p. were sufficiently large for power purposes. With the introduction of ball and compeb mills carrying heavy charges of metallic grinding medium, and the building of larger units, motors of much larger capacity were required. The modern tube mill uses a motor within the range of 200 to $600 \mathrm{~h}$. p.

Being essentially a constant-speed load, there would seem to be no question but that the synchronous motor, operating at unity power factor, would be the obvious selection. The tube mill, however, requires 140 per cent to 150 per cent of full motor torque to start, even under the most favorable conditions, and the synchronous motor is not capable of exerting this high torque during the starting period. Slip-ring motors were, therefore, quite generally adopted for this service.

During this stage of development of cement grinding machinery, marked improvements were being made in the construction of magnetic clutches which were installed in large numbers in rubber mills and similar industries. Rubber mills at first made use of magnetic clutches as safety stop devices, but in 1913, synchronous motors were introduced for rubber mill drives and the magnetic clutches were used to bring the mill lines up to speed after the motor had been started light. This practise of using synchronous motors and magnetic clutches in rubber mills grew rapidly and there were soon hundreds in service throughout the country.

In 1918 , a certain manufacturing company began using synchronous drive for compeb mills and installed the first unit in one of the plants of a large cement company. The combination of synchronous motor and magnetic clutch proved to be as satisfactory in the cement industry as in other industries. Other installations quickly followed and, at the present time, there are oyer fifty units in operation in the United States, India and Australia.

TORQUE REQUIREMENTS

It is the usual practise to select a clutch capable of transmitting the maximum horse power which the motor can develop. That is, if a cement mill motor rated at 400 h. p. normal will develop 800 h. p. maximum, the clutch should be capable of transmitting $800 \mathrm{~h}$. p. or over, depending upon the ratings of the standard magnetic clutches on the market. The clutch may be considerably larger than actually required without danger to the machine, and for this reason, some manufacturers find it desirable to use a single size of clutch to take care of a range of mill sizes in order to gain the benefits of standardization.

Operation of Magnetic Clutch

The principle of operation of a magnetic clutch is clearly shown in Figs. 1A and 1B. The field member is an electro-magnet containing an annular coil, and the armature member serves as the armature or keeper which is drawn towards the field member when the coil

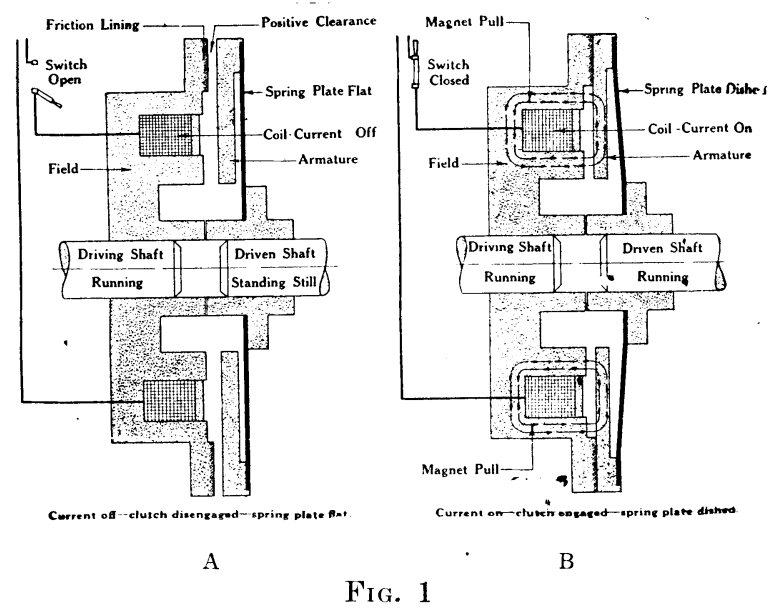

is energized. On the outer rim of the field member is a flange carrying a friction surface, and the armature member is extended to come into engagement with this friction surface. When no current is flowing in the coil, the armature member stands a short distance away from the friction surface giving a positive running clearance. When it is desired to engage the clutch, the coil is connected to the line through a suitable switch and the magnetism produced in the field member draws the armature member against the friction lining. The friction between the lining and the armature member drives the load.

\section{Starting the Tube Mill}

It has been found in practise that a tube mill can safely be started by connecting the clutch directly to the line, and allowing the mill to come up to speed as quickly as the clutch permits. The results obtained by this method show that the starting period may be as short as five seconds, which in the opinion of some motor builders is too short a time to be considered 
good practise. Time, however, in this case is not a measure of the safety to the machinery, since it is only a question of the forces imposed on the various sections of the units. The clutch torque-transmitting capacity being limited to approximately twice the motor torque, it is plain that the forces transmitted cannot exceed the allowable forces figured by the machine designers as safe.

Mill operators in the past have expressed a preference for a manually operated rheostat to control the excitation of the clutch during the starting period, and most of the clutches in this service are equipped with such starters. The type of starter used for this service is very simple, being of the same construction as the starter used for a five-h. p. direct-current motor, except that a special resistor layout is used. Such a starter allows the clutch torque to be regulated within limits, and the starting period can be extended several seconds longer than the starting period when no rheostat is used.

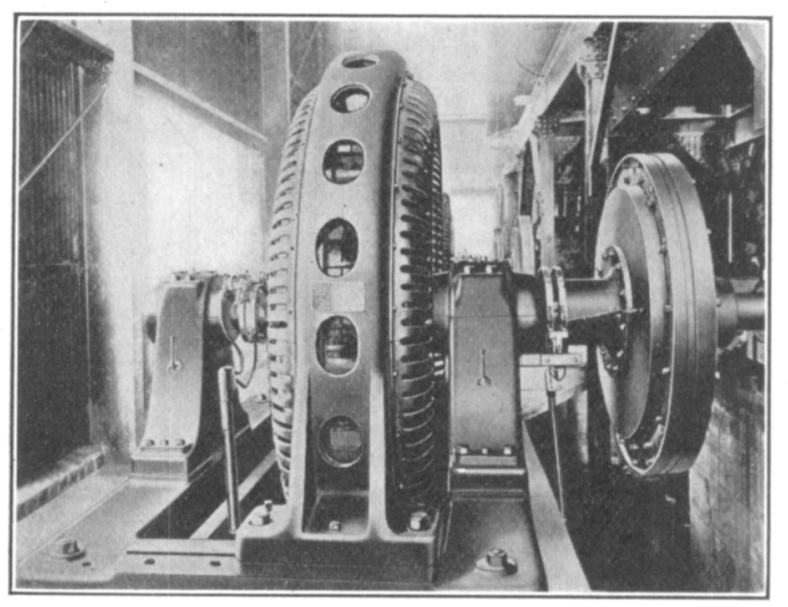

Fig. 2-Sixty-Inch Magnetic Clutches with Synchronous Motors Driving Compeb Mills in a Cement Plant

Other operators energize the clutch by closing an enclosed line switch and use no form of rheostat. Starting conditions with this operation are equally as satisfactory as when a rheostat is used. An understanding of the magnetic clutch characteristics makes clear why satisfactory starting can be expected without the use of a rheostat. A large electromagnet, such as used in the magnetic clutch, is highly inductive, and introduces a time element in the growth of the magnetic flux. Laboratory experiments have shown that it requires approximately six seconds for the average-size clutch, used in cement mill service, to reach its maximum torque after the switch is closed and full voltage is impressed at the clutch terminals.

During the first few seconds that the clutch is energized, the torque capacity is not sufficient to start the mill, and the clutch will continue to slip. During this period, however, the clutch is impressing upon the mill shaft gradually increasing torque which takes up all slack in the gears, etc. Therefore, when the clutch torque is great enough to start the mill in rotation the pull is steady and no shock is experienced, just as would be expected from a clutch having these characteristics.

There is one objection to the use of a starting rheostat. The starter may be held in a position which does not allow sufficient current to flow through the clutch coil to start the mill. For example, consider that the compeb mill requires 150 per cent full motor torque before it will start to turn. The starting rheostat may be held in a position where the clutch will not develop more than 125 per cent full motor torque. Under these conditions, the clutch would slip continuously and would never start the mill. The result would be unnecessary wear of the lining, and heating of the clutch. The standard practise of the manufacturers of magnetic clutches is to furnish clutches without rheostats, unless rheostats are specified.

\section{Direct CuRRent Required}

Magnetic clutches require direct current for excitation, and 110 or 220 volts is suitable. The exciter generator for the synchronous motor often serves as a source of direct current for the magnetic clutch, though frequently direct current is supplied from an outside source.

\section{SHAFT ALINEMENT}

The two shafts on which the clutch members are mounted must be kept in exact alinement, if the equipment is to run without vibration. Several methods are employed to keep the shafts in alinement. The simplest and in many ways most satisfactory method is to use a three-bearing motor base plate having the clutch mounted between two of the bearings. With this arrangement, it is a relatively easy matter to maintain the shaft in correct alinement, after the installation has been made on a solid foundation. Most of the synchronous motors now in service are of the twobearing type. There is no possible objection to this arrangement, except that it is necessary to check the shaft alinement more frequently than when a threebearing base plate is used. Flexible couplings, both in combination with the magnetic clutch and separate from it are used with the standard two-bearing motors, and the three-bearing motors. Flexible couplings give a measure of relief from shaft misalinement and are preferred by some operators while others consider them an additional complication.

The problems entering into the design and application of clutches to cement mill services are more of a mechanical than an electrical nature, that is, the greatest problem is to build a clutch which will give years of continuous and reliable service under the conditions encountered in practise. Magnetic clutches have an advantage over clutches of any other type because the force required for the operation is developed 
within the clutch structure itself instead of being transmitted from an outside source by means of sliding collars, toggles, etc. It is therefore, the simplicity of the mechanical design which is one of the most pronounced features of the magnetic clutch. It is of course highly desirable to use a clutch which may be operated simply by closing a switch, as contrasted with a mechanical clutch which may require one or several men to engage it. Reliable operation is, however, the greatest demand.

\title{
The Economics of Direct Current Railway Distribution With Particular Reference to the Automatic Substation
}

\author{
BY LAWRENCE P. CRECELIUS \\ Member, A. I. E. E. \\ and \\ VICTOR B. PHILLIPS \\ Consulting Engineers, Cleveland, $\mathrm{O}$.
}

Review of the Subject.-The comparatively recent development of the full automatic substation and also the automatic substation combined with remote control, has served to re-open the entire subject of the economics of distribution. But quite aside from the questions that the automatic substation has presented, the great fluctuations in the prices of materials and of labor have made necessary renewed study of this subject. In other words, the proper design of a distribution system should represent a balance between all of the different items of cost that go to make up the total cost of power. Any change in the relative cost of materials as against labor or of a certain class of materials as against another class of materials tends to upset such a balance. Now that we begin to emerge from the unsettled conditions of the past few years during which the old relationships have been substantially changed, it is necessary to ask the question whether or not the rules by which distribution systems have been planned in the past still apply.

More specifically, it is the purpose of this paper to determine, first, the relations that govern the size of feeders and the correct feeder layouts for any given arrangement of substations, and second, the principles underlying the correct location, size, and type of substations, assuming the fullest development of automatic and semi-automatic control.

There is involved also the important question of stray currents. Regardless of the merits of the electrolysis controversy, the minimizing of stray currents is certainly to be desired by the electric railways. The most effective method of accomplishing this is increasing the number of distributing points. If a large number of distributing points be justified from an economic standpoint, and if furthermore this be found practicable from an operating standpoint, then the problem of electrolysis may perhaps cease to exist. Thus the inquiry is doubly pertinent.

The cost of distribution in large cities of the size of Cleveland, Detroit, or St. Louis, comprising the carrying charges on the feeder, the heating losses in the feeders and the carrying charges on the equipment necessary to supply these losses, is considerably in excess of $\$ 200,000$ per year. It is apparent that a careful study of this item of cost will more than likely be justified by the savings that will result.

There are not at the present time sufficient accurate data on cost and performance of automatic substations to make possible a precise analysis of specific cases. In lieu of this it is the authors' purpose to show limiting conditions and by example to illustrate the relation of the various determining factors to the final cost.

\section{CONTENTS}

Review of the Subject.

1. Feeder Circuits.

2. Rail and Ground Circuits.

3. Entire Distribution Circuits.

4. Distribution Distances Variable with Variable Load.

5. Generating Plant, Transmission Line and Substation Investment.

6. Operating Expenses (Generating Plant, Transmission Lines and Substations)

7. Economically Correct Substation Layouts

8. Conclusions.
(a) Common practise in regard to feeder sizes.
(b) Relative Importance of substation efficiency.
(c) Methods of operation and their effect upon substation efficiency and total cost of power.
(d) Limitations to increasing number of substations.
(e) Standardization of equipment on a system.

\section{Feeder Circuits}

$\mathrm{T}$

E total cost of feeder distribution comprises the following:

(1) Carrying charges on feeder investment.

(2) Carrying charges on (a) generating plant, (b) transmission lines, and (c) substations, for that part of the investment that supplies the losses in the feeders.

(3) Operating expenses of the generating plant, transmission lines and substations for that energy which is lost through heating of the feeders.

In cities of about the size of Cleveland the following conditions are fairly representative:

To be presented at the Annual Convention of the A.I.E.E., Niagara, Falls, Ont., June 26-30, 1922.
(1) Feeder investment, $\$ 1,000,000$. Carrying charges

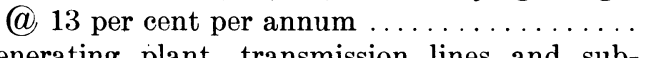

(2) Generating plant, transmission lines and substation investment per kw. (d-c.) demand, $\$ 165$.

At 14 per cent per annum these carrying charges are $\$ 23$ per $\mathrm{kw}$.

Maximum demand, 40,000 kw. Distribution loss during peak, 10 per cent. Carrying charges, $0.10 \times 40,000 \times \$ 23$

92,000

(3) Operating expenses of generating plant, transmission lines and substations.

0.8 cent per kw-hr.

$140,000,000 \mathrm{kw}-\mathrm{hr}$. at 40 per cent load factor 2.5 per cent average dist ribution loss-

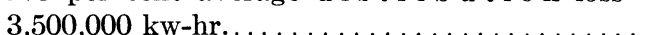

Total 